\title{
Review of Diabetes Management System \& Tactics
}

\author{
Fiza Shaikh $^{1}$, Vanshika Srivastava ${ }^{2}$, Er. Chandan Prasad ${ }^{3}$ \\ B. Tech Scholar, CTIS, School of Information \& Technology, Pune, India ${ }^{1}$ \\ BCA Scholar, CTIS, School of Information \& Technology, Pune, India ${ }^{2}$ \\ Assistant Professor, IT, Ajeenkya DY Patil University, Pune, India ${ }^{3}$
}

\begin{abstract}
Now a day's environment is not containing fresh air as it was present in past or we can say ancient time was far-far better than the current because population and pollution was not big challenge in our country and in world too. Due to presence various pollutant in environment it is tough to live healthy life. Various diseases are evolved in current days due these extensive polluted environment. The impact of this factor is in resultant of less organic food, infected foods and more. Diabetes is a continual condition affecting on average about $9 \%$ of the population, mostly type II with about. $4 \%$ diagnosed with type I diabetes mellitus. The condition poses multiple challenges to patients who fight back daily with the burden of monitoring, care, restrictive routine and the stress inherent to the health and life threatening nature of the condition. While there is proof in the existing literature supporting the pivotal role of emotions and emotion regulation in diabetic management, the evidence lacks in organization and conceptualization. The relatively new perception of emotional intelligence holds promise of providing an organizing framework for our perceptive of the ways in which emotions are involved in determining diabetic management outcomes.
\end{abstract}

Keywords: Diabetes, Impaired Glucose Tolerance (IGT), Impaired Fasting Glucose (IFG), Type 1, Type 2, Type 3, Fasting Plasma Glucose (FPG), Oral Glucose Tolerance Test (OGTT), Raspberry pi, Raspbian OS, Pressure Sensor, and Key Generation.

\section{INTRODUCTION}

Diabetes Mellitus is a chronic, life threatening metabolic condition of a cumulative, increasingly critical nature, manifested in multisystem failures, inflicting suffering, stress, decreased quality of life and in time disability and death [1]. Diabetes case commonness ranges 2-21\% in adult populations around the globe, and varies considerably across cultures, socioeconomic class and gender. Among younger populations Type I diabetes occurrence ranges $0.2-2 \%$ depending on the above factors.

The existing data suggests that the conditions prevalence will increase by $50-100 \%$ in the next 20 years, making it a modern day epidemic, taking its toll on individuals, their families, support systems and of course a huge burden on health systems, employment organizations and other systems. The condition, once diagnosed, requires adherence to a strict, restrictive life style (e.g.: diet, exercise, etc.), and a painful monitoring and treatment regimen (e.g.: frequent blood tests, insulin injections, etc.). Given this reality, the literature has long examined the emotional and social implications of living with diabetes.

The evidence gathered across more than 40 years of research suggests that emotional responses and experience may play a role in the conditions onset, course, treatment effectiveness and outcomes. In this paper I focus on the emotional aspects of the conditions management, often involving frustration, enduring pain and discomfort, conflict and ongoing stress, that are said to both increase physical susceptibility to complications as well as hinder appropriate and effective monitoring, care and adherence to treatment plans.

\section{LITERATURE SURVEY}

In India and all around the world the medical sector is enhanced in terms of digitalization ferociously in past 20years. With the speedy environment changes and continuous social progression in our country, people's production and routine are undergoing reflective changes, accordingly resulting in health issues and increasingly severe challenges on the inadequate organic food resources.

Prediabetes Before people develop type 2 diabetes, they almost always have "prediabetes" — blood glucose levels that are higher than normal but not yet high enough to be diagnosed as diabetes.

Doctors sometimes refer to prediabetes as impaired glucose tolerance (IGT) or impaired fasting glucose (IFG), depending on what test was used when it was detected. This condition puts you at a higher risk for developing type 2 diabetes and cardiovascular disease. 


\section{ISO 3297:2007 Certified}

Vol. 5, Issue 3, March 2017

There are several ways to diagnose diabetes. Each way usually needs to be repeated on a second day to diagnose diabetes. Testing should be carried out in a health care setting (such as your doctor's office or a lab). If your doctor determines that your blood glucose level is very high, or if you have classic symptoms of high blood glucose in addition to one positive test, your doctor may not require a second test to diagnose diabetes.

\section{TABLE I ANALYSIS CHART OF DIFERENT TESTS}

\begin{tabular}{|c|c|c|}
\hline AlC & FPG & OGTT \\
\hline Diabetes & Diabetes & Diabetes \\
$\geq 6.5 \%$ & $\geq \mathbf{1 2 6} \mathbf{m g} / \mathrm{dl}$ & $\geq \mathbf{2 0 0} \mathrm{mg} / \mathrm{dl}$ \\
$<6.5 \%$ & $<\mathbf{1 2 6} \mathbf{~ m g} / \mathrm{dl}$ & $<\mathbf{2 0 0} \mathrm{mg} / \mathrm{dl}$ \\
Prediabetes & Prediabetes & Prediabetes \\
$\geq 5.7 \%$ & $\geq \mathbf{1 0 0} \mathrm{mg} / \mathrm{dl}$ & $\geq \mathbf{1 4 0} \mathrm{mg} / \mathrm{dl}$ \\
$<5.7 \%$ & $<\mathbf{1 0 0} \mathrm{mg} / \mathrm{dl}$ & $<\mathbf{1 4 0} \mathrm{mg} / \mathrm{dl}$ \\
Normal & Normal & Normal \\
\hline
\end{tabular}

A1C:

The A1C test measures your average blood glucose for the past 2 to 3 months. The advantages of being diagnosed this way are that you don't have to fast or drink anything.

Diabetes is diagnosed at an $\mathrm{A} 1 \mathrm{C}$ of greater than or equal to $6.5 \%$.

TABLE III ANALYSIS RESULT OF TEST

\begin{tabular}{|c|c|}
\hline Result & A1C \\
\hline Normal & Less than $5.7 \%$ \\
\hline Prediabetes & $5.7 \%$ to $6.4 \%$ \\
\hline Diabetes & $6.5 \%$ or higher \\
\hline
\end{tabular}

Fasting Plasma Glucose (FPG):

This test checks your fasting blood glucose levels. Fasting means after not having anything to eat or drink (except water) for at least 8 hours before the test. This test is usually done first thing in the morning, before breakfast. Diabetes is diagnosed at fasting blood glucose of greater than or equal to $126 \mathrm{mg} / \mathrm{dl}$.

\section{TABLE IIIII ANALYSIS RESULT OF TEST}

\begin{tabular}{|c|c|}
\hline Result & FGP \\
\hline Normal & Less than $100 \mathrm{mg} / \mathrm{dl}$ \\
\hline Prediabetes & $100 \mathrm{mg} / \mathrm{dl}$ to $125 \mathrm{mg} / \mathrm{dl}$ \\
\hline Diabetes & $126 \mathrm{mg} / \mathrm{dl}$ or higher \\
\hline
\end{tabular}

Oral Glucose Tolerance Test (OGTT):

The OGTT is a two-hour test that checks your blood glucose levels before and 2 hours after you drink a special sweet drink. It tells the doctor how your body processes glucose.
Diabetes is diagnosed at 2 hour blood glucose of greater than or equal to $200 \mathrm{mg} / \mathrm{dl}$

\section{TABLE IVII ANALYSIS RESULT OF TEST}

\begin{tabular}{|c|c|}
\hline Result & OGTT \\
\hline Normal & Less than $140 \mathrm{mg} / \mathrm{dl}$ \\
\hline Prediabetes & $140 \mathrm{mg} / \mathrm{dl}$ to $199 \mathrm{mg} / \mathrm{dl}$ \\
\hline Diabetes & $200 \mathrm{mg} / \mathrm{dl}$ or higher \\
\hline
\end{tabular}

The importance of factors peripheral to the self in diabetes management was acknowledged by Paterson et al. Who drew attention to the role of health care professionals in (Paterson et al., 2001) "transformative" experiences; they conceptualized this as a self-motivated, interpersonal process between doctor and patient and suggested that when it works well, it offers patients a great deal of reimbursement. However, insufficient interaction with healthcare professionals could lead to a lack of trust and leaving behind of self-management recommendations. Therefore, the management of diabetes appears to operate on multiple levels: first, internally, in terms of personal identity, and self, but also externally, in terms of cultural resources and inter-subjective realities of medical consultations. A study conducted in Pakistan on diabetes knowledge, beliefs and practices among people with diabetes provided evidence that there was a lack of information available to people with diabetes in Pakistan as a large percentage of the population has never received any diabetes education on self-management at all.

This study may have under estimated the extent of the problem as it was conducted in an urban university hospital setting, where diabetes education may be more readily available compared to rural areas where people have less access to information and may have even poorer understanding of diabetes and the importance of selfmanagement practices. As per the existing system, patients have to invest money before knowing their diagnosis report. They have to visit diagnostic centre, consult their doctor and wait for a day to get their result. If someone have only doubt and want to have a check-up, then it will have their wastage of money and time for them. Each time you have to provide your basic information and go through the same diagnosis process to get your diagnosis result which can be dangerous in some serious condition. Patients should go through the check-up process immediately before the diagnosis process, if such condition arises. So keeping patients records and searching their records manually sometimes not possible and sometime it's a time taking process.

\section{III.PROPOSED SYSTEM}

Technology can be used to complement healthcare provider diabetes care by providing both educational and motivational support. Technology can enlarge the reach of 


\section{ISO 3297:2007 Certified}

Vol. 5, Issue 3, March 2017

diabetes education and support when primary care resources are insufficient or patient resources and access to care are inadequate [2]. Patients may have difficulty scheduling and attending diabetes education classes or meeting frequently with a diabetes educator due to time, financial, or other constraints [3]. Education can be provided using technological resources so that patients learn new practices and routines related to diabetes management. Technology can support the daily diabetes self-management activities of blood glucose monitoring, exercising, healthy eating, taking medication, monitoring for complications, and problem-solving. Visual feedback of clinical information, including these self-management activities, improves patient's ability to see how diabetes is affected by their behaviours and promotes decisionmaking and problem-solving. Monitoring of selfmanagement behaviours can be motivational and allows for more frequent contact between patients and healthcare providers. This can lead to necessary changes in selfmanagement behaviours and treatment plans [4]. Internet diabetes interventions provide opportunities to offer diabetes education, support, and motivation for selfmanagement behaviours. Web-based learning provides easy access without time or location restrictions and allows users to work at their own pace.

Your path to good health just got a lot easier.

Just enter some basic health information and calculate your risk for:-

- Level 1

- Level 2

- Level 3

Once you calculates your risk, you can quickly see the difference simple lifestyle changes — such as losing weight or quitting smoking — can make in your overall risk.

You will receive a personal action plan outlining suggestions for lowering your risk for these deadly diseases.

This system will provide the future of medical system which can be embedded in wearable devices and web based system.

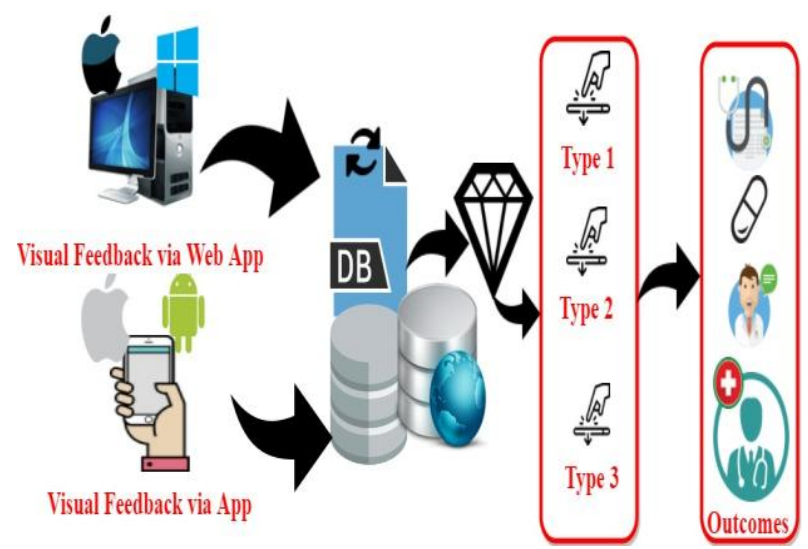

The proposed system, in execution not lone diminish barrier but cut the annoyances of a safe diagnosis and instance result in terms of medication or doctor visit if necessary.

\section{IV.CONCLUSION}

The adaptability of the innovative technology which saves lots of money and instant solutions allows marvelous flexibility when realizing the various doctors' opinion. The proposed system will improve the medication approach by developing software, which is cost-effective, would be a major improvement. Due to the current high investment, costs related with real-time it's not easy to affordable by everyone.

The innovative medication solutions approach has an extensive range of applications. This approach maybe realistic in various types of persons such as kid, adult and old etc. Many would help from the use of this tactic, local governments, universities, medical Institutions and in conclusion the public.

\section{REFERENCES}

[1] Guariguata L, Whiting DR, Hambleton I, Beagley J, Linnenkamp U, Shaw JE. Global estimates of diabetes prevalence for 2013 and projections for 2035. Diabetes Res Clin Pract. 2014 Feb;103(2):137-49. doi: 10.1016/j.diabres.2013.11.002. Epub 2013 Dec 1.

[2] http://www.diabetes.org/are-you-atrisk/prediabetes/?referrer=http://www.diabetes.org/are-you-atrisk/diabetes-risk-test/?loc=alertday\#sthash.HQgCItH8.dpuf

[3] https://www.ncbi.nlm.nih.gov

[4] www.mayoclinic.org/diseases.../diabetes/in-depth/diabetesmanagement/art-20047963

[5] www.emedicine.medscape.com/article/117853-treatmen

[6] https://www.diabetesaustralia.com.au/managing-type-2

[7] Bond GE. Lessons learned from the implementation of a Webbased nursing intervention. Comput Inform Nurs. 2006;24:66-74.

Fig. 1. Proposed System Architecture 